\title{
O QUE O GOLPE QUER CALAR: LITERATURA E POLÍTICA NO BRASIL HOJE
}

\author{
What the coup wants to silence: literatura and politcs in Brazil, today \\ Regina Dalcastagnè* \\ Universidade de Brasília
}

\begin{abstract}
Este texto é uma homenagem ao Cau Cancellier, ferido pelas engrenagens do golpe.
\end{abstract}

\begin{abstract}
Resumo: Para se consolidar, o golpe de 2016 tem de conter o movimento de democratização que, de algum modo, se fortalecia no país nos últimos anos, especialmente a partir do acesso à educação pública e com a valorização dos espaços periféricos de produção cultural. Esse golpe se estabelece, então, contra os direitos das mulheres, dos negros, dos indígenas, dos trabalhadores, dos moradores das periferias, da população LGBT, dos pobres; contra sua inserção social e contra suas formas de expressão. Mas se estabelece, também, contra o ensino público, contra a liberdade de expressão e de cátedra, contra o pensamento crítico. Mais do que nunca, precisamos estar atentos às vozes que eles querem calar, ao que elas têm a nos dizer, ao que elas acrescentam na compreensão de nossa realidade e na ampliação dos recursos estéticos disponíveis para reinterpretar o mundo. Este texto pretende fazer parte desse processo de resistência, discutindo algumas possibilidades de escrita em tempos de recrudescimento dos discursos fascistas.
\end{abstract}

Palavras-chave: Golpe de 2016. Literatura. Política. Liberdade. Crítica literária.

Abstract: In order to consolidate itself, the 2016 "soft coup" in Brazil must contain the democratization movement that strengthened in the country in the last years, especially by the access to public education and the valorization of the peripheral spaces of cultural production. The coup was against the rights of women, of Black and indigenous people, of workers, of the inhabitants of the peripheries, of the LGBT population; against their social insertion and against their forms of expression. But it also was against public education, against freedom of expression and teaching, against critical thinking. More than ever, we need to be attentive to the voices that they want to keep silent, to what they have to tell us, to what they add to our understanding of our reality and to the widening of the aesthetic resources available to reinterpret the world. This text intends to be part of this process of resistance, discussing some possibilities of writing in times of exacerbation of fascist discourses.

\section{Esta obra está licenciada sob uma Creative Commons - Atribuição 4.0}

\footnotetext{
* Professora titular de literatura brasileira da Universidade de Brasília, coordenadora do Grupo de Estudos em Literatura Brasileira Contemporânea e pesquisadora do CNPq. E-mail: rdal@unb.br.

(iD) https://orcid.org/0000-0003-2251-8022
}

Anu. Lit., Florianópolis, v. 23, n. 2, p. 13-24, 2018. ISSNe 2175-7917 
Keywords: 2016 coup. Literature. Politics. Freedom. Literary criticism.

Recebido em: 27/04/2018

Aceito em: 02/06/2018

É um prazer estar aqui com vocês hoje, nessa universidade que também é minha ${ }^{1}$. Entrei aqui, no curso de Jornalismo, em 1985, na euforia do fim da ditadura, e me mudei para Brasília em 1989 - para fazer um mestrado em literatura - na euforia da promulgação da nova Constituição Federal. Poderia pontuar toda a minha vida acadêmica com a vida política deste país, incluindo aí os investimentos públicos feitos em pesquisas sobre a representação literária de grupos marginalizados e o incentivo às políticas de cotas, que mudaram o perfil das universidades públicas no Brasil e criaram, para mim, também, um lugar mais fértil, a partir de onde acreditava poder fazer algo pela nossa sociedade, ao lado de pessoas que acreditam na mesma coisa.

Daí veio o golpe de 2016. Um golpe em pleno andamento - daqui mesmo podemos ouvir sua maquinaria perversa, que inclui perseguições, ameaças, gritos, pedradas, tiros, seriados de televisão, assassinatos de lideranças populares, de gente que luta pelos direitos humanos, de vereadoras negras de esquerda, de meninos pretos que militavam culturalmente em suas comunidades e de outros tantos, que só queriam viver suas vidas. Um golpe que tem como objetivo a destruição dos direitos trabalhistas, a entrega das riquezas do país ao capital internacional, a divisão do butim entre os banqueiros, os latifundiários, os especuladores, os donos da grande mídia. Um golpe que, para se consolidar, tem de conter o movimento de democratização que, de algum modo, se fortalecia no país, especialmente com o acesso à educação superior e com a valorização dos espaços periféricos de produção cultural.

Esse golpe se estabelece, então, contra os direitos das mulheres, dos negros, dos indígenas, dos trabalhadores, dos moradores das periferias, da população LGBT, dos pobres; contra sua inserção social e contra suas formas de expressão. Mas se estabelece, também, contra o ensino público, contra a liberdade de expressão e de cátedra, contra o pensamento crítico, contra nossos sonhos de justiça. Por isso mesmo, mais do que nunca, precisamos estar atentos às vozes que eles querem calar, ao que essas vozes têm a nos dizer, ao que elas acrescentam na compreensão de nossa realidade e em termos de ampliação dos recursos estéticos disponíveis para reinterpretar o mundo.

Se antes já me parecia impossível entender a literatura desenraizada da sociedade que a gerou e que a sustenta, agora acho ainda mais urgente reinserir a discussão sobre a literatura brasileira contemporânea em seu contexto político e social, buscando - como todos - alguma coisa que nos explique como diabos chegamos até aqui. E procurando, ainda, ferramentas para o contraponto a esses discursos contaminados que nos cercam, discursos fascistas, equivocados, vazios de sentido e carregados de ódio. A literatura se torna, assim, um espaço de interlocução e um abrigo. Não toda ela, porque a arte também pode servir aos poderosos, domesticada e

\footnotetext{
${ }^{1}$ Este texto, com pequenos ajustes e o mesmo título, é a palestra apresentada na UFSC no dia 29 de março de 2018.
} 
conivente. Me refiro aquela literatura que nos ajuda a refletir sobre nosso lugar no mundo e sobre o lugar do outro, sobre como o nosso conforto pode estar atrelado à situação desesperadora de tantas pessoas. Interessa a literatura que nos permite pensar junto e ampliar as possibilidades de questionamento do mundo.

O historiador francês Lucien Bianco dizia que "as armas dos fracos são sempre fracas armas" (apud BOURDIEU, 1998, p. 38), mas é com elas que teremos que lutar. Nossas soluções, agora, serão provisórias, angustiadas, desesperançadas, até, mas talvez nos permitam ficar de pé enquanto as coisas não mudam. Podemos usar o discurso, nossa arma principal, para referendar o que querem os poderosos (como fazem, inclusive, alguns colegas e escritores), mas também podemos usá-lo para desmascará-los ou, mesmo, para tirar-lhes o sossego. É tempo de disputar consciências e tentar preservar espaços democráticos de enunciação de discursos, de representações do mundo.

Ainda vamos tomar esse país de volta, e se a luta agora é pelos direitos mais básicos, que escorrem entre nossos dedos - incluindo aposentadoria, saúde, moradia, educação pública e liberdade de expressão - não podemos deixar que nos façam retroceder tanto a ponto de perdermos nossa capacidade de refletir sobre as desigualdades que nos forjam e sobre a necessidade de democratizar, de fato, diferentes espaços sociais, como o espaço acadêmico e o cultural.

E, por menor que seja esse nosso restrito circuito acadêmico e literário, temos muitas frentes de resistência aqui. Elas podem ir desde a produção de autoras e autores negros, indígenas, pobres e de periferia, de autores que insistem em fazer arte em um mundo que nega valor à sua experiência, e mesmo à sua vida; até a recente retomada da ditadura como tema literário, por exemplo, com o resgate de memórias apagadas e a sinalização de riscos que não são passado, mas, infelizmente, possível futuro para nós.

A resistência passa, ainda, pelo esforço de pequenas editoras, de pequenas livrarias, de jornalistas combativos ( $\mathrm{sim}$, eles ainda existem), de coletivos de escritoras e escritores que estão se organizando, nesse instante mesmo, para manter abertos espaços de publicação e divulgação da literatura. Todo um conjunto de pessoas que buscam, de algum modo, se erguer contra o amesquinhamento do mundo e o desmonte de nossa cultura.

Outra dessas frentes passa pela nossa atuação como professores e críticos literários, pelo necessário apoio aos nossos estudantes e orientandos em suas escolhas e em suas dificuldades, pessoais, econômicas, políticas. E passa - não poderia deixar de ressaltar - pela resistência ao nosso próprio conceito de literatura, ao enquadramento que damos ao literário, ao que aprendemos ser o bom, o belo, o correto, o legítimo, à nossa tendência a excluir tudo aquilo que escapa desses contornos tão pré-estabelecidos.

Não custa lembrar que obras de escritoras/escritores negros, indígenas, periféricos, de mulheres e mesmo jovens fora do eixo e fora do mercado, causam - em diferentes medidas e proporções - uma dissonância em um campo literário que se quer harmônico, estável e consolidado. A disputa por espaço que esses autores e autoras empreendem não é algo que determinados grupos, determinados críticos e determinados escritores (muito certos de sua 
própria superioridade) aceitam entender como legítima².

A negação da validade dessas expressões é, como já disse, um dos objetivos desse golpe. A elite brasileira não aguenta ver sua empregada doméstica disputando a vaga do vestibular com seus filhos, não suporta vê-la como professora, não aceita imaginá-la como uma pesquisadora, como uma escritora, como uma artista. Mas elas estão aí, talvez aqui dentro mesmo! E é sobre a escrita de algumas delas que vou falar hoje, muito brevemente.

Cabe a nós a reflexão sobre os significados dessa disputa e o sentido - estético e político - dessas obras. Se eximir dessa discussão é, muitas vezes, já se situar - do lado daqueles que ocupam as posições centrais no campo literário e social. Ser indiferente não me parece ser uma opção hoje, se é que algum dia já foi. Afinal, participar do debate político em um momento de ruptura da democracia, contaminar a própria escrita, ou a crítica, em busca do desmascaramento de um processo autoritário é ainda acreditar - nos homens e mulheres e na própria literatura como instrumento de ação. Quando desistirmos de nossa capacidade de acreditar, a luta, enfim, estará perdida.

E, por favor, não me entendam mal, não estou dizendo aqui que a literatura possa nos salvar dos idiotas e fascistas que nos cercam. Eles vão continuar por aí, humilhando as pessoas, perseguindo os que pensam diferente deles, batendo, torturando, esmagando ossos, como sempre fizeram. A literatura não é pílula de humanização, ela é (ou pode ser) ferramenta para aqueles que se dispõem a refletir sobre seu lugar no mundo e sobre o lugar do outro.

Acho que não conseguiria explicar isso melhor do que com um exemplo. Trago o poema de Eliane Marques, jovem poeta gaúcha. Ela é negra, advogada e auditora pública externa do Tribunal de Contas do Estado do Rio Grande do Sul. É filha de uma empregada doméstica, para horror de nossa classe média. O poema, intitulado "intervenção federal", foi publicado em 21 de fevereiro de 2018 em um blog chamado "A voz pública da poesia”, de Porto Alegre:

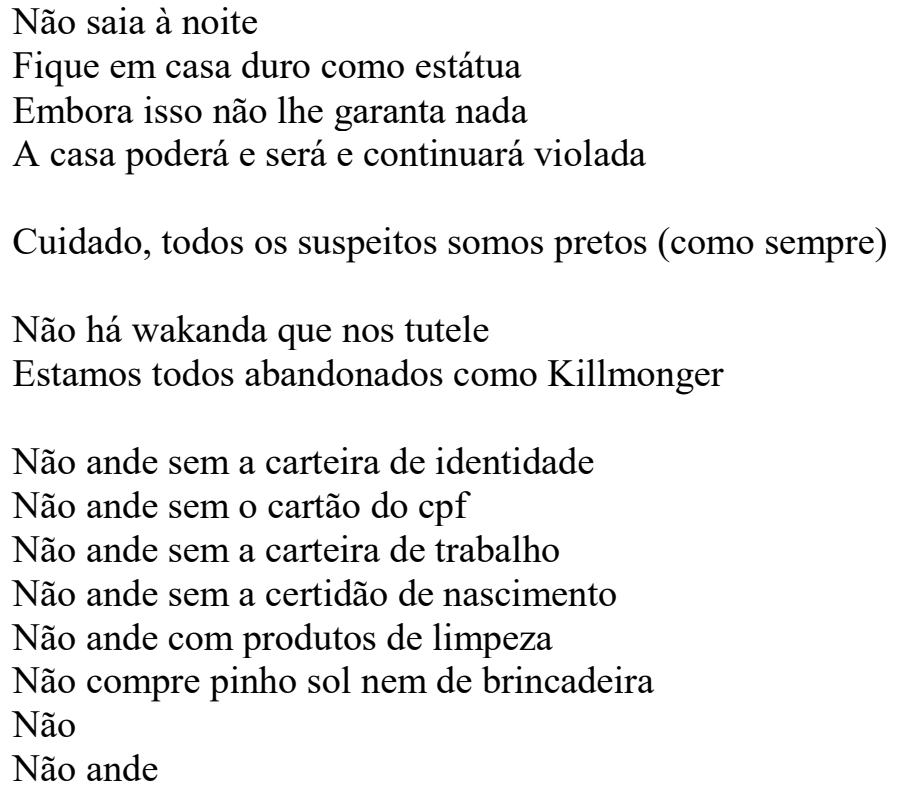

\footnotetext{
${ }^{2}$ Para uma discussão mais aprofundada sobre questões vinculadas à representação e ao campo literário brasileiro, ver Dalcastagnè (2012 e 2015).
}

Anu. Lit., Florianópolis, v. 23, n. 2, p. 13-24, 2018. ISSNe 2175-7917 
Talvez o seu próximo assassinado seja evitado

Com uma certidão de nascido morto

Por isso não fale não balbucie

Cale a boca do cachorro

Em caso de smartphones ou câmeras fotográficas

Carregue a nota fiscal e as suas instruções de uso

Carregue cenas de você os recebendo na loja

Dizem que o que os olhos não o coração não sente

Não carregue guarda-chuvas longos (nem de noite e nem de dia)

Podem sugerir um fuzil AR 15 ou uma metralhadora HK

Não utilize furadeiras

Podem ser confundidas com uma pistola e o disparo das suas balas

Não carregue bolsas

Podem sugerir que você carrega uma bomba

Não sente na frente da casa

Não sente nos fundos da casa

Não sente dentro da casa

Você não tem casa nem janelas

E as Dora Milaje estão ocupadas

- Buscam o corpo de seus filhos mortos

Bom, parece trágico e exagerado

Mas também não teremos covas e nem carpideiras que nos chorem.

(MARQUES, 2018)

Há nesse texto um intenso diálogo com o presente, que começa, obviamente, na “intervenção federal” iniciada em fevereiro deste ano nas favelas do Rio de Janeiro (e que nos parece, perigosamente, um ensaio - lá, onde a vida é mais fragilizada - para uma intervenção militar no país). Do fato em si, o poema remete à sua representação em diferentes mídias sociais, com seu racismo introjetado e seu preconceito de classe contra preto pobre, com o eterno discurso sobre sua periculosidade: “Cuidado!”. Mas, aqui, a perspectiva social de quem fala é outra: "Cuidado, todos os suspeitos somos pretos (como sempre)". O verbo, na primeira pessoa do plural, "somos", marca o lugar de fala da autora no contexto social e racial brasileiro. Já o "como sempre", que aparece entre parênteses, faz a rápida e inevitável correlação histórica com o passado. Libertos os escravos, eles passam a ser a ameaça que cerca as fazendas, as cidades. A ameaça que deve ser controlada, cercada, confinada em espaços como as favelas, silenciada.

(Se quiserem saber mais sobre isso, há muitos títulos da História, mas leiam Diário de Bitita (1986), de Carolina Maria de Jesus, onde ela lembra das coisas que lhe contava seu avô sobre o fim da escravidão e sobre o lugar que sobrou aos negros, quando foram expulsos das fazendas sem poder levar nem uma trouxa nas mãos).

Há a remissão, ainda, às manifestações de 2013 e à injustiça cometida contra Rafael Braga, preso e condenado com suas garrafas de pinho-sol e água sanitária.

O ritmo do poema é dado por outro discurso atual. Vocês devem ter assistido a um vídeo

Anu. Lit., Florianópolis, v. 23, n. 2, p. 13-24, 2018. ISSNe 2175-7917 
no youtube de três jovens negros, Edu Carvalho, AD Junior e Spartakus Santiago, explicando como os negros deveriam se comportar durante a "intervenção": não saia assim, não faça isso, não carregue aquilo. É um vídeo sério e absolutamente constrangedor para qualquer um que consiga perceber que são brasileiros, estudantes, professores, faxineiras, garçons, crianças, pessoas iguaizinhas a nós que passam por essa afronta, nas ruas, dentro de suas casas, todos os dias... São milhares de cidadãos, para alguns poucos bandidos que, é claro, não serão intimidados por isso.

Há também, no poema, as referências a um outro universo, imaginário, do filme Pantera Negra, que estreou faz pouco tempo no Brasil, e marca um momento importante de representação não estereotipada para a comunidade negra. Ou seja, o poema não nasce do gênio isolado - essa aberração sem cor, gênero, classe social, endereço, orientação sexual, idade. Do gênio criador que, em seu gabinete intocado, indaga a vida e reflete sobre a existência. O poema nasce com os pés sujos de barro, lambuzado nos acontecimentos, imerso nos discursos que circulam em diferentes canais, carregando raiva, dor e história compartilhada. E é por isso que ele nos interessa, que ele tem importância no mundo.

O poema de Eliane Marques é um grito de revolta, é um lamento, mas é também um acalanto para a vida, porque para os negros não há "covas nem carpideiras que os chorem".

Como lidar com esse poema? Em primeiro lugar, vamos ignorá-lo porque não está publicado em um livro? Aguardar até que seja publicado? Talvez nunca seja. Por isso ele tem menos valor? É menos sofisticado, menos complexo do que outros tantos do passado ou do presente que já estão referendados? E qual o nosso papel como estudiosos da literatura? Estou falando de vocês, também, estudantes, não só de seus professores. Estou colocando essas questões porque dentro do nosso universo acadêmico, dentro dos estudos literários, ainda há gente que ignora completamente um material como esse, e o desmerece.

Estudar literatura não significa se fechar em um quarto com um livro e não levantar a cabeça dele. Muito pelo contrário, sem olhar ao redor é impossível entendê-lo. Por isso, os estudos literários dependem, fortemente, de outras áreas de conhecimento - da História, da Antropologia, da Sociologia, da Filosofia, em alguns casos talvez até da Matemática, da Física. E dependem da nossa sensibilidade para escolher e acessar as melhores ferramentas para interpretar o nosso objeto. (Por isso, também, a preocupação com a retirada de várias dessas disciplinas do currículo do ensino médio - num processo com objetivos claramente autoritários e que nos remetem diretamente aos anos 1960 e à ditadura civil-militar.)

Estudar literatura pode parecer uma futilidade, diante da necessidade que esse país tem de médicos, dentistas, engenheiros etc. Mas cuidado! É isso que eles querem que a gente pense. Dizem o mesmo de todas as áreas de Humanas. Para que História, Sociologia, Antropologia, Filosofia, afinal? São áreas que sempre tiveram menos recursos financeiros e que agora estão sendo estranguladas. São áreas que geram conhecimento crítico, que incitam - ou deveriam incitar - o desejo de transformação da sociedade.

Eu dizia antes que a literatura é um modo de se refletir sobre o mundo, mas é também um modo de se inserir nele. Por isso todo um esforço para que determinadas pessoas (pobres,

Anu. Lit., Florianópolis, v. 23, n. 2, p. 13-24, 2018. ISSNe 2175-7917 
negras, periféricas, mulheres) não escrevam e, se escreverem, não sejam lidas, e, se forem lidas, não sejam reconhecidas como escritoras. Vou dar dois breves exemplos que, acredito, deixarão claro porque essa escrita é um ameaça, e a quem ela ameaça. Os dois exemplos envolvem um nome que não pode mais ser ignorado ao se falar de literatura brasileira (embora a gente saiba bem que é muitas vezes esquecido): me refiro a Carolina Maria de Jesus.

O primeiro exemplo é o da escritora Conceição Evaristo, outra mulher negra, que foi empregada doméstica e hoje é um nome importantíssimo da literatura brasileira. Ela conta, em entrevista, do desejo de escrita que surge em sua mãe, também empregada doméstica, quando se viu diante de Quarto de despejo (1983), de Carolina Maria de Jesus:

Nas páginas da outra favelada nós nos encontrávamos. Conhecíamos, como Carolina, a aflição da fome. E daí ela percebeu que podia escrever como a outra, porque ela era também a Outra... São lindos os originais de minha mãe, caderninhos velhos, folhas faltando, exteriorizando a pobreza em que vivíamos. Ali, para além de suas carências, ela se valeu da magia da escrita e tentou, como Carolina, manipular as armas próprias do sujeito alfabetizado. (EVARISTO, 2011, p. 105).

Se a dona Joana preencheu seus caderninhos pobres com sua visão de mundo, a voz de sua filha ecoa entre nós, como no belíssimo poema "Vozes-mulheres", de Conceição Evaristo (1990, p. 32-33):

A voz de minha bisavó ecoou

criança

nos porões do navio.

Ecoou lamentos

De uma infância perdida.

A voz de minha avó

ecoou obediência

aos brancos-donos de tudo.

A voz de minha mãe ecoou baixinho revolta

No fundo das cozinhas alheias

debaixo das trouxas

roupagens sujas dos brancos

pelo caminho empoeirado

rumo à favela.

A minha voz ainda

ecoa versos perplexos

com rimas de sangue

$\mathrm{e}$

fome.

A voz de minha filha

recorre todas as nossas vozes

recolhe em si

as vozes mudas caladas 
engasgadas nas gargantas.
A voz de minha filha
recolhe em si
a fala e o ato.
O ontem - o hoje - o agora.
$\mathrm{Na}$ voz de minha filha
se fará ouvir a ressonância
o eco da vida-liberdade.

O segundo exemplo atravessa o oceano. Traduzido e depois resumido em uma revista francesa, Quarto de despejo chegou até uma outra empregada doméstica, uma martiniquense emigrada para a França durante a II Guerra. Françoise Ega era uma mulher de 40 anos em 1962, mãe de cinco filhos pequenos, sem nenhum tempo livre. Tocada pelo que entendeu ser uma experiência comum entre os seus, resolveu escrever um livro inteiro como uma carta a Carolina, uma mulher que ela nunca veria e que, sabia bem, jamais a leria. Lettres a une noire (Cartas a uma negra), que começou a ser produzido em 1962 e só foi publicado em 1978, após a sua morte (e a de Carolina Maria de Jesus), é um impressionante apelo à compreensão de sua própria existência e do desespero de outras imigrantes em condições ainda piores do que as dela.

Assim como Dona Joana, a mãe de Conceição Evaristo, Françoise Ega se reconhece na escrita de Carolina, lembrando que "as misérias dos pobres do mundo inteiro se parecem como irmãs" (EGA, 1978, p. 9, tradução nossa). Por isso decide começar esse livro, para evitar que essas histórias de vida fossem apagadas, como tantas outras. Mas segue fazendo-o por uma necessidade própria, como se usasse o "diálogo" estabelecido para refletir sobre sua escrita e, de algum modo, aplacar sua angústia. Seus filhos riem de seu esforço, seu marido debocha de sua presunção. Ela mesma chega a duvidar do que está fazendo, mas prossegue:

Faz um mês que parei de escrever, de falar com você, Carolina, porque meu primogênito riu, ele me disse com sua lógica infantil que era ridículo escrever a uma pessoa que jamais me lerá. Eu sei, eu repito isso para mim em um sussurro, mas ele me disse em alto e bom som, tanto que seus irmãos repetiram em coro: "Rá! Por que você diz coisas a Carolina? Ela não fala francês". Nós não falamos a mesma língua, é verdade, mas o idioma do nosso coração é o mesmo e é bom se encontrar em algum lugar, onde nossas almas se juntem. Hoje, eu retomei minha serenidade e converso com você, eu me sinto tranquila. (EGA, 1978, p. 24, tradução nossa).

A literatura é importante porque ela é uma arma de empoderamento, porque, nas mãos certas, ela rompe com o discurso hegemônico sobre o mundo, ela nos dá acesso a outras perspectivas sobre a vida e as relações que estabelecemos aqui. Dominar essa ferramenta é um ato revolucionário por si só, por isso tão perigoso. Porque a escrita contamina, no bom sentido do termo - ela convida a fazer também. Mas a elite dominante quer ser a única a falar, é claro, para impor os seus valores, as suas razões, como sempre fez - e a classe média burra aplaude, porque pensa que assim fica mais perto dos poderosos do que da situação difícil daqueles que têm de lutar por cada centímetro do terreno. 
Nós, dentro das instituições de ensino públicas, precisamos saber de que lado queremos estar, de que lado devemos estar. É mais do que hora de riscar o chão e dizer "daqui vocês não passam", "aqui vocês não entram", "na minha amiga, no meu aluno, na moça que viaja comigo, no motorista do meu ônibus vocês não tocam”. Já perdemos muito território, levaremos anos, talvez décadas para reconquistá-lo, mas há um limite de até onde podemos calar. E acho que esse limite é agora.

Nós, das Letras, precisamos nos juntar ao movimento de resistência que, enfim, vem se formando dentro das universidades públicas a partir da tentativa de censura à disciplina sobre "O golpe de 2016 e o futuro da democracia no Brasil”, lá da Universidade de Brasília. A discussão, que nasce em um departamento de Ciência Política e se expande por mais de 50 universidades em atividades interdisciplinares, precisa estar em nossos departamentos, também, em nossos programas de pós-graduação. Precisamos nos articular e dar nossa resposta, junto de poetas e ficcionistas, ao que está acontecendo neste momento. Ou vamos aguardar, covardemente, para ver no que dá? Esperando para nos mostrarmos combativos, um dia, sobre os destroços.

Gostaria de finalizar com uma imagem e um último poema. A imagem é do século XIX, dos primórdios da fotografia, quando ela não era acessível a todos (e seus dispositivos não podiam ser carregados dentro do bolso traseiro da calça). Durante séculos, gerações viviam e morriam sem ter uma única imagem registrada. A fotografia permitiu isso, a materialização da memória, dos afetos. No entanto, muitas vezes alguém querido falecia antes que se tivesse tempo de fotografá-lo. Daí o surgimento de toda uma série de técnicas para fotografar pessoas já mortas como se estivessem vivas: suportes metálicos para a sustentação dos corpos, maquiagem apropriada antes e pintura na pós-produção da fotografia, entre outras estratégias próprias de cada fotógrafo para cada situação ${ }^{3}$.

Com a popularização da fotografia tudo isso foi desaparecendo, é claro. Mas lembrem que as primeiras câmeras fotográficas - os daguerreótipos - exigiam um tempo de exposição muito longo, para que a imagem se fixasse na película de prata que recobria a placa de cobre. Por isso as fotos antigas trazem figuras tão rígidas, porque ninguém podia se mexer ou a imagem ficaria desfocada.

\footnotetext{
${ }^{3}$ Para mais informações e fotos, ver Bafflegabbler (2011).
} 
Fotografia 1: O que respira

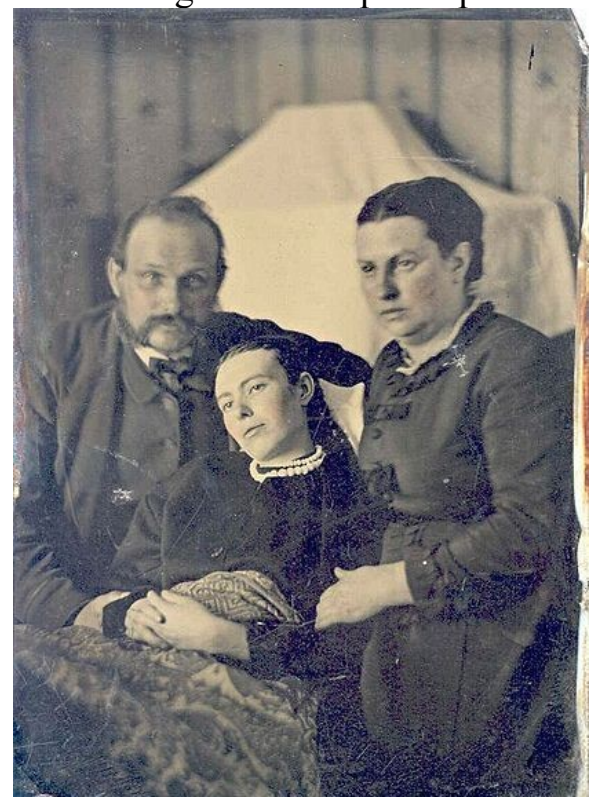

Fonte: Bafflegabbler (2011).

Nesta foto, a filha está morta. Reparem como seu rosto é tranquilo e nítido. Enquanto isso, os rostos dos pais perdem clareza e foco.

É que respirar gera movimento. Estar vivo impossibilita a fixidez.

Trago essa imagem, em sua tristeza contida, como uma metáfora sobre a necessidade do movimento para confirmar a vida, e da necessidade de nos deslocarmos para enxergar o que está vivo ao nosso redor, nos deslocarmos de nossos conceitos fechados, de nossas ideias prontas, que sufocam e paralisam. E não importa que percamos um pouco o chão que nos protege, que não consigamos ver com nitidez completa aquilo que queremos entender, descrever, analisar - é preciso apostar na fertilidade da vida, mesmo quando tudo à nossa volta parece negar suas possibilidades.

Esse é, para mim, o nosso mais significativo gesto de resistência, em direção aos outros e ao imponderável. E a literatura... pode ser um delicado convite para esse movimento. Como no poema de Micheliny Verunschk, publicado em sua página no facebook, no dia 18 de março de 2018, com o qual encerro, mesmo, minha fala. Porque não vamos baixar a cabeça, porque não vamos entregar nossas "fracas armas", porque não vamos desistir das palavras que nos tornam humanos:

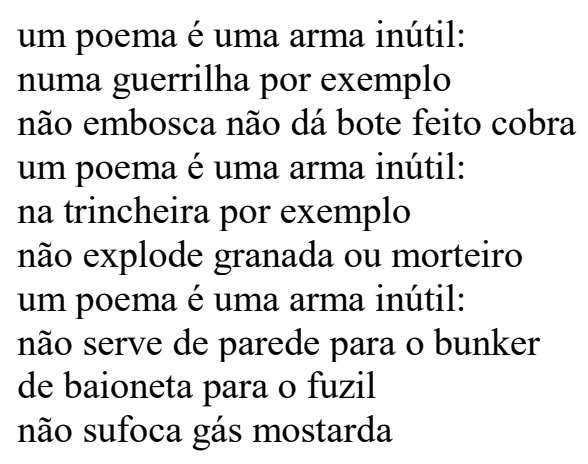


numa guerra um poema é quase nada falta-lhe a contundência que é da arma numa guerra um poema é quase nada falta-lhe a potência de ferir que é da bala numa guerra um poema é quase nada falta-lhe o fio de metal que apunhala numa guerra um poema é só palavra chão amor amada casa mãe beijo bússola mapa numa guerra um poema é só palavra e isso basta.

(VERUNSCHK, 2018)

\section{Referências}

BAFFLEGABBLER. Memento More: victorian era postmortem photography. Maio de 2011. Disponível em: https://ostrobogulation.com/2011/05/11/memento-mori-victorian-erapostmortem-photography/. Acesso em: 20/06/2018.

BOURDIEU, Pierre. La domination masculine. Paris: Seuil, 1998.

CARVALHO, Edu, AD Junior e Spartakus Santiago. Vídeo: Intervenção no Rio: como sobreviver a uma abordagem indevida. 17 de fevereiro de 2018. Disponível em: https://www.youtube.com/watch?v=eBdSBmTFR5g. Acesso em: 20/06/2018.

DALCASTAGNÈ, Regina. Literatura brasileira contemporânea: um território contestado. Rio de Janeiro/Vinhedo: Editora da UERJ/Horizonte, 2012.

DALCASTAGNÈ, Regina. Representación y resistencia en la literatura brasileña contemporánea. Buenos Aires: Biblos, 2015.

EGA, Françoise. Lettres à une noire. Paris: L'Harmattan, 1978.

EVARISTO, Evaristo. Depoimento. In: DUARTE, Eduardo de Assis e Maria Nazareth Soares Fonseca (orgs.). Literatura e afrodescendência no Brasil. v. 4. Belo Horizonte: Editora UFMG, 2011.

EVARISTO, Conceição. Vozes-mulheres. Cadernos Negros n. 13, São Paulo: Quilomhoje, 1990, p. 32-33.

JESUS, Carolina Maria de. Diário de Bitita. Rio de janeiro: Nova Fronteira, 1986.

Quarto de despejo. 10. ed. Rio de Janeiro: Francisco Alves, 1983.

MARQUES, Eliane. Intervenção federal. A voz pública da poesia. Disponível em: http://avozpublicadapoesia.blogspot.com.br/2018/02/intervencao-federal.html. Acesso em: 25/04/2018. 
VERUNSCHK, Micheliny. Sem título. Disponível em: https://www.facebook.com/search/top/?q=on $\% \mathrm{C3} \% \mathrm{~A} 7 \mathrm{a} \% 20$ verunschk $\% 20 \mathrm{um} \% 20$ poema $\% 2$ 0\%C3\%A9\%20uma\%20arma\%20in\%C3\%BAtil\%3A. Acesso em: 25/04/2018.

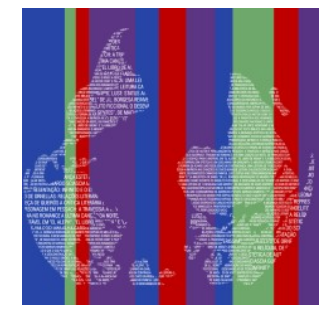

